\title{
Nomogram for Predicting the Prognosis of Patients with Hepatocellular Carcinoma Presenting with Pulmonary Metastasis
}

This article was published in the following Dove Press journal: Cancer Management and Research

\author{
Yongjie Zhou ${ }^{\mathrm{I}-3, *}$ \\ Xin Zhou ${ }^{1,3, *}$ \\ Jingqin $\mathrm{Ma}^{\mathrm{l}-3}$ \\ Wen Zhang ${ }^{1-3}$ \\ Zhiping Yan ${ }^{1-3}$ \\ Jianjun Luo ${ }^{1,4}$
}

'Department of Interventional Radiology, Zhongshan Hospital, Fudan University, Shanghai, People's Republic of China; ${ }^{2}$ Shanghai Institution of Medical Imaging, Shanghai, People's Republic of China; ${ }^{3}$ National Clinical Research Center for Interventional Medicine, Zhongshan Hospital, Fudan University, Shanghai, People's Republic of China; ${ }^{4}$ Center for Tumor Diagnosis and Therapy, Jinshan Hospital, Fudan University, Shanghai, People's Republic of China

*These authors contributed equally to this work
Correspondence: Jianjun Luo; Zhiping Yan Department of Interventional Radiology, Zhongshan Hospital, Fudan University, No. 180 Fenglin Road, Shanghai, 200032, People's Republic of China Email luo.jianjun@zs-hospital.sh.cn; yan.zhiping@zs-hospital.sh.cn
Background: Only a few studies have investigated the clinical features and outcomes of patients with pulmonary metastasis from hepatocellular carcinoma (HCC) at the initial diagnosis. This study aimed to evaluate the prevalence, risk factors and prognostic factors related to pulmonary metastasis and then construct a nomogram to predict the outcomes of patients with HCC presenting with pulmonary metastasis.

Methods: The Surveillance, Epidemiology, and End Results (SEER) database was used to select patients. A total of 25,236 eligible patients diagnosed with HCC from 2010 to 2015 were selected. Then, 897 patients with HCC presenting with pulmonary metastasis at the initial diagnosis were included in the primary set $(n=598)$ and validation set $(n=299)$. Logistic and Cox regression analyses were used to determine the risk factors and prognostic factors for pulmonary metastasis. A nomogram predicting the prognosis of patients with HCC presenting with pulmonary metastasis was constructed based on independent prognostic factors identified in Cox regression analyses. Both internal and external validations of the nomogram were performed using discrimination and calibration plots.

Results: The prevalence of pulmonary metastasis was 3.6\% $(897 / 25,236)$ in the entire cohort diagnosed with $\mathrm{HCC}$ as the initial diagnosis. Age, race, Edmonson-Steiner classification grade I/III, higher $\mathrm{T}$ stage, $\mathrm{N}$ stage, alpha fetoprotein(AFP) levels, brain metastasis, bone metastasis and intrahepatic metastasis were positively correlated with the development of HCC with pulmonary metastasis at the initial diagnosis. Prognostic factors incorporated in the nomogram were sex, $\mathrm{T}$ stage, bone metastasis, AFP levels, treatment, radiation and chemotherapy. The concordance index (C-index) of the nomogram in the primary set was 0.661 (95\% CI: $0.633-0.688)$, indicating considerable predictive accuracy. The calibration curves showed consistency between the nomogram and the actual observations. When the nomogram was applied to the validation set, the results also remained reconcilable, and the C-index of the nomogram was 0.657 (95\% CI: 0.626-0.698).

Conclusion: A list of risk factors associated with pulmonary metastasis occurrence in patients with HCC was selected, and the nomogram accurately predicted the prognosis of patients with HCC presenting with pulmonary metastasis at the initial diagnosis.

Keywords: hepatocellular carcinoma, pulmonary metastasis, nomogram, (SEER) database

\section{Introduction}

Hepatocellular carcinoma (HCC) is the most common cancer and the third leading cause of cancer-related deaths worldwide. ${ }^{1}$ Several therapies, including liver resection, transplantation and ablation, are potential curative methods for early-stage disease. $^{2,3}$ However, most patients in China are diagnosed with advanced or even 
end-stage HCC, which is always associated with vascular invasion and extrahepatic metastasis. The most frequent site of extrahepatic metastasis in patients with HCC is the lung, followed by lymph nodes, bone, and brain. ${ }^{4}$

The incidence of pulmonary metastasis in patients with $\mathrm{HCC}$ is relatively low but is frequently associated with a poor prognosis and shorter survival. ${ }^{5}$ Specific treatments are not available for this set of patients other than the recommended guidelines for advanced HCC, which includes systemic treatment, transarterial chemoembolization (TACE) and radiation. ${ }^{2,3}$ Currently, fewer investigations have been conducted concerning the clinical characteristics and prognosis of patients with HCC presenting with pulmonary metastasis. Moreover, due to the relatively low incidence, no clinicopathological characteristics of HCC with pulmonary metastasis or recognized staging systems have sufficient predictive prognostic value for this set of patients. Hence, a summary of characteristics and a more accepted and easy-to-operate model for predicting prognosis are needed to identify variables associated with the development of pulmonary metastasis in patients with HCC and improve the prognosis of patients with HCC presenting with pulmonary metastasis.

Nomograms have been widely used in clinical practice due to their precise value and convenience for predicting the prognosis of many tumors. ${ }^{6-8}$ In this study, we first evaluated the prevalence and risk factors for pulmonary metastases in patients with HCC and further identified prognostic factors to construct a nomogram for patients with HCC presenting with pulmonary metastasis using data from the Surveillance, Epidemiology, and End Results (SEER) database.

\section{Materials and Methods}

\section{Database and Patient Selection}

The Surveillance, Epidemiology, and End Results (SEER) program (1973-2015) is a cancer registry that contains information on patients with cancer and is supported by the National Cancer Institute and Centers for Disease Control and Prevention. Patients who were diagnosed with primary HCC between 2010 and 2015 were selected because information on metastases was not recorded before 2010 . The primary site was code $\mathrm{C} 22.0$, and histological types were codes $8170 / 3-8175 / 3$ to identify HCC. The patients were considered eligible for this study if they met the following criteria: 1) aged $>18$ years, 2) survival time $>1$ month, and 3 ) adequate clinical information was available.
From January 1, 2010 to December 31, 2015, 25,236 patients identified as having HCC were included in our study to further analyze the pulmonary metastasis prevalence and risk factors. Data from 897 patients who were initially diagnosed with HCC with pulmonary metastasis were extracted and constituted another cohort for further analysis to analyze risk factors. We randomly divided the aforementioned cohort into one primary training cohort $(n=598)$ and one validation cohort $(n=299)$. A nomogram was established for the primary cohort and validated using the validation cohort.

\section{Statistical Analysis}

Categorical variables were evaluated using the chi-square test or Fisher's exact test. We identified the risk factors for patients initially diagnosed with HCC and pulmonary metastasis using a logistic regression model. The independent prognostic factors for survival were determined using Cox hazards models. The backward step-down process based on the Akaike information criterion (AIC) was performed to finally identify independent prognostic factors. Both the odds ratios (ORs) and the hazard ratios (HRs) with their 95\% confidence intervals (95\% CIs) were calculated. We used overall survival as the primary endpoint, which was defined as the interval from the date of diagnosis until the date of death or the last day of follow-up. A nomogram with several significant prognostic factors identified using the Cox hazard models was established using R software (version 3.5.1, https://www. r-project.org/). We further assessed the performance of the nomogram using Harrell's concordance index (C-index), where a larger value indicates higher prognostic value. Calibration curves for our nomogram were depicted to explain the concordance between the predicted survival and the observed survival. The statistical analysis was performed using R software (version 3.5.1) and GraphPad Prism software version 6.0 (GraphPad Software, Inc., La Jolla, CA). All tests were two-sided, and $\mathrm{p}<0.05$ was considered statistically significant.

\section{Results}

\section{Prevalence of HCC with Pulmonary Metastasis}

According to the inclusion criteria, 25,236 patients were enrolled. The characteristics and demographics of patients with HCC presenting with or without pulmonary metastasis are presented in Tables 1 and 2 . The 
Table I Multivariable Logistic Regression Analysis of Characteristics of Patients with Hepatocellular Carcinoma Presenting with Pulmonary Metastasis at the Initial Diagnosis (\%)

\begin{tabular}{|c|c|c|c|c|c|}
\hline \multirow[t]{2}{*}{ Characteristics } & \multirow[t]{2}{*}{ Total } & \multicolumn{2}{|c|}{ HCC Patients (20 I0-20I5) } & \multirow[t]{2}{*}{ OR (95\% Cl) } & \multirow[t]{2}{*}{$P$ value } \\
\hline & & With PM & Without PM & & \\
\hline Patients & 25,236 & $897(3.6)$ & $24,339(96.4)$ & - & - \\
\hline \multicolumn{6}{|l|}{ Age } \\
\hline$<50$ & 1388 & 81 (5.8) & I 307 (94.6) & I(Reference) & 1 \\
\hline $50-60$ & 7346 & $277(3.1)$ & 7069 (96.9) & $0.73(0.56-0.98)$ & $0.03 *$ \\
\hline $60-70$ & 9281 & $285(3.1)$ & $8996(96.9)$ & $0.62(0.47-0.82)$ & $<0.001^{*}$ \\
\hline $70-80$ & 4917 & $169(3.4)$ & $4748(96.6)$ & $0.75(0.56-1.02)$ & 0.06 \\
\hline$>80$ & 2304 & $85(3.7)$ & $2219(96.3)$ & $0.85(0.60-1.19)$ & 0.34 \\
\hline \multicolumn{6}{|l|}{ Race } \\
\hline White & 17,327 & $534(3.1)$ & 16,793 (96.9) & I(Reference) & 1 \\
\hline Black & 3508 & $168(4.8)$ & 3340 (95.2) & $1.36(1.12-1.64)$ & $0.002 *$ \\
\hline Other** & 4401 & $195(4.4)$ & $4206(95.6)$ & $1.45(1.21-1.74)$ & $<0.001^{*}$ \\
\hline \multicolumn{6}{|l|}{ Sex } \\
\hline Female & 5934 & $192(3.2)$ & $5742(96.8)$ & I (Reference) & I \\
\hline Male & 19,302 & $705(3.7)$ & $18,597(96.3)$ & $1.01(0.84-1.20)$ & 0.951 \\
\hline \multicolumn{6}{|c|}{ Edmonson-Steiner classification } \\
\hline Unknown & 16,406 & $583(3.6)$ & $15,823(96.5)$ & I (Reference) & I \\
\hline 1 & 2736 & $57(2.1)$ & 2679(97.9) & $0.73(0.54-0.96)$ & $0.03 *$ \\
\hline II & 4168 & $127(3.0)$ & $4041(97.0)$ & $0.95(0.77-1.56)$ & 0.60 \\
\hline III & 1800 & $120(6.7)$ & $1680(93.3)$ & $1.43(1.14-1.76)$ & $0.001^{*}$ \\
\hline IV & 126 & $10(7.9)$ & $116(92.1)$ & $1.78(0.84-3.36)$ & 0.10 \\
\hline \multicolumn{6}{|l|}{ T stage } \\
\hline TI & 12,259 & $236(1.9)$ & $12,023(98.1)$ & I(Reference) & I \\
\hline $\mathrm{T} 2$ & 5997 & 114 (1.9) & $5883(98.1)$ & $0.90(0.7 I-1.13)$ & 0.39 \\
\hline T3 & 6154 & $408(6.6)$ & $5746(93.4)$ & $2.4 I(2.02-2.87)$ & $<0.001^{*}$ \\
\hline $\mathrm{T} 4$ & 826 & $139(16.8)$ & $687(83.2)$ & $5.96(4.67-7.58)$ & $<0.001^{*}$ \\
\hline \multicolumn{6}{|l|}{$N$ stage } \\
\hline No & 23,504 & $679(2.9)$ & $22,825(97.1)$ & I(Reference) & I \\
\hline $\mathrm{NI}$ & 1732 & $218(12.6)$ & I5I4 (87.4) & $2.38(1.98-2.85)$ & $<0.001^{*}$ \\
\hline \multicolumn{6}{|l|}{ Bone metastasis } \\
\hline None & 24,499 & 754 (3.I) & 23,745 (96.9) & I (Reference) & I \\
\hline Yes & 737 & 143 (19.4) & $594(80.6)$ & $4.40(3.47-5.55)$ & $<0.001^{*}$ \\
\hline
\end{tabular}


Table I (Continued).

\begin{tabular}{|c|c|c|c|c|c|}
\hline \multirow[t]{2}{*}{ Characteristics } & \multirow[t]{2}{*}{ Total } & \multicolumn{2}{|c|}{ HCC Patients (2010-20I5) } & \multirow[t]{2}{*}{ OR (95\% Cl) } & \multirow[t]{2}{*}{$P$ value } \\
\hline & & With PM & Without PM & & \\
\hline \multicolumn{6}{|l|}{ Brain metastasis } \\
\hline None & 25,183 & $879(3.5)$ & $24,304(96.5)$ & I (Reference) & I \\
\hline Yes & 53 & $18(34.0)$ & $35(66.0)$ & $6.75(3.48-12.63)$ & $<0.001^{*}$ \\
\hline \multicolumn{6}{|c|}{ Intrahepatic metastasis } \\
\hline None & 25,045 & $821(3.3)$ & $24,224(96.7)$ & I (Reference) & I \\
\hline Yes & 191 & $76(39.8)$ & $115(60.2)$ & $6.94(3.48-12.63)$ & $<0.001^{*}$ \\
\hline \multicolumn{6}{|l|}{ AFP } \\
\hline Unknown & 4038 & $|2|(3.0)$ & $3917(97.0)$ & I (Reference) & I \\
\hline Elevated & 15,244 & $680(4.5)$ & $14,564(95.5)$ & $1.05(0.85-1.30)$ & 0.64 \\
\hline Normal & 5954 & $96(1.6)$ & $5858(98.4)$ & $0.56(0.42-0.74)$ & $<0.001^{*}$ \\
\hline \multicolumn{6}{|l|}{ Insurance status } \\
\hline Uninsured & 11,027 & $367(3.3)$ & $10,660(96.7)$ & I (Reference) & I \\
\hline Insured & 14,209 & $530(3.7)$ & $13,679(96.3)$ & $0.94(0.8 I-1.10)$ & 0.42 \\
\hline \multicolumn{6}{|l|}{ Marital status } \\
\hline Unmarried & $\mid 1,021$ & $40 I(3.6)$ & $10,620(96.4)$ & I (Reference) & I \\
\hline Married & 14,215 & $496(3.5)$ & $13,7 \mid 9(96.5)$ & $0.88(0.76-1.02)$ & 0.09 \\
\hline
\end{tabular}

Notes: ${ }^{*}$ Indicates significance of $\mathrm{P}<0.05 .{ }^{*}$ Indicates American Indian/AK Native, Asian/Pacific Islander, and unknown.

Abbreviations: HCC, hepatocellular carcinoma; PM, pulmonary metastasis; AFP, alpha fetoprotein; OR, odds ratio; $\mathrm{Cl}$, confidence interval.

prevalence of pulmonary metastasis was $3.6 \%$ (897/ $25,236)$ in the entire cohort initially diagnosed with HCC. Overall, most patients with HCC presenting with pulmonary metastasis were male $(78.6 \%)$, white $(59.5 \%)$, married $(55.3 \%)$ and insured $(59.1 \%)$. In terms of age, most patients were diagnosed at ages of $60-70$ years (31.8\%), followed by 50-60 (30.9\%), 70-80 (18.8\%), $>80(9.5 \%)$ and $<50(9.0 \%)$ years. Notably, $75.8 \%$ of patients presented elevated levels of alpha fetoprotein(AFP), and approximately equal numbers of patients had grade II $(14.2 \%)$ or III $(13.4 \%)$ tumors according to the Edmondson-Steiner classification. Regarding the T stage, most patients were diagnosed with T3 stage (45.5\%), followed by T1 (26.3\%), T4 (15.5\%), and T2 (12.7\%). A small proportion of patients were diagnosed with multiple metastases, such as bone (15.9\%), liver (8.5\%) and brain $(0.2 \%)$ metastases. No significant differences in the clinical characteristics or demographics of the patients were observed between the primary and validation sets, as shown in Table 2.

\section{Risk Factors for Developing Pulmonary Metastasis in Patients with HCC}

Risk factors associated with the development of pulmonary metastasis in patients with HCC were analyzed using univariate and multivariate logistic regression models, as presented in Table 1. Based on our results, age, race, Edmonson-Steiner classification grade I/III, higher T stage, N stage, AFP levels, brain metastasis, bone metastasis and intrahepatic metastasis were positively correlated with the development of pulmonary metastasis in patients with $\mathrm{HCC}$ at the initial diagnosis.

\section{Prognostic Factors for the Overall Survival of Patients with HCC Presenting with Pulmonary Metastasis}

During follow-up, $94.4 \%(\mathrm{~N}=565)$ of patients with HCC presenting with pulmonary metastasis at the initial diagnosis who were included in the primary cohort died. As shown in Table 3, after the univariate analysis, sex, Edmonson-Steiner 
Table 2 Comparison of Characteristics of the Primary and Validation Sets (\%)

\begin{tabular}{|c|c|c|c|c|}
\hline Characteristics & All Patients & Primary Set & Validation Set & $P$ value \\
\hline Patients & 897 & 598 & 299 & \\
\hline Age & & & & 0.824 \\
\hline$<50$ & $81(9.0)$ & $54(9.0)$ & $27(9.0)$ & \\
\hline $50-60$ & $277(30.9)$ & $192(32.1)$ & $85(28.4)$ & \\
\hline $60-70$ & $285(31.8)$ & $186(31.1)$ & $99(33.1)$ & \\
\hline $70-80$ & $169(18.8)$ & $112(18.8)$ & $57(19.1)$ & \\
\hline$>80$ & $85(9.5)$ & $54(9.0)$ & $31,910.4)$ & \\
\hline Race & & & & 0.389 \\
\hline White & $534(59.5)$ & $362(60.5)$ & $172(57.5)$ & \\
\hline Black & $168(18.7)$ & $114(19.1)$ & $54(18.1)$ & \\
\hline Other** & $195(21.7)$ & $122(20.4)$ & $73(24.4)$ & \\
\hline Sex & & & & 0.730 \\
\hline Female & $192(21.4)$ & $126(2||)$. & $66(22.1)$ & \\
\hline Male & $705(78.6)$ & $472(78.9)$ & $233(77.9)$ & \\
\hline Edmonson-Steiner classification & & & & 0.921 \\
\hline Unknown & $583(65.0)$ & $387(64.7)$ & $196(65.6)$ & \\
\hline 1 & $57(6.4)$ & $38(6.4)$ & $19(6.4)$ & \\
\hline II & $127(14.2)$ & $82(13.7)$ & $45(15.1)$ & \\
\hline III & $120(13.4)$ & $84(14)$ & $36(12.0)$ & \\
\hline IV & $10(1.1)$ & $7(1.2)$ & $3(1.0)$ & \\
\hline T stage & & & & 0.889 \\
\hline TI & $236(26.3)$ & $156(26.1)$ & $80(26.8)$ & \\
\hline $\mathrm{T} 2$ & $114(12.7)$ & $79(13.2)$ & $35(11.7)$ & \\
\hline T3 & $408(45.5)$ & $273(45.7)$ & $135(45.2)$ & \\
\hline $\mathrm{T} 4$ & $139(15.5)$ & $90(15.1)$ & $49(16.4)$ & \\
\hline$N$ stage & & & & 0.660 \\
\hline No & 679(75.7) & $450(75.3)$ & $229(76.6)$ & \\
\hline $\mathrm{NI}$ & $218(24.3)$ & I 48 (24.7) & $70(23.4)$ & \\
\hline Bone metastasis & & & & 0.949 \\
\hline None & $754(84.1)$ & $503(84.1)$ & $25 I(83.9)$ & \\
\hline Yes & $143(15.9)$ & 95 (15.9) & $48(16.1)$ & \\
\hline Brain metastasis & & & & 1 \\
\hline None & $879(98.0)$ & $586(98.0)$ & $293(98.0)$ & \\
\hline Yes & $18(0.2)$ & $12(0.02)$ & $6(0.02)$ & \\
\hline
\end{tabular}


Table 2 (Continued).

\begin{tabular}{|c|c|c|c|c|}
\hline Characteristics & All Patients & Primary Set & Validation Set & $P$ value \\
\hline Intrahepatic metastasis & & & & 0.397 \\
\hline None & $821(91.5)$ & $544(91.0)$ & $277(92.6)$ & \\
\hline Yes & $76(8.5)$ & $54(9.0)$ & $22(7.4)$ & \\
\hline AFP & & & & 0.219 \\
\hline Unknown & $121(13.5)$ & $89(14.9)$ & $32(10.7)$ & \\
\hline Elevated & $680(75.8)$ & 447 (74.7) & $233(77.9)$ & \\
\hline Normal & $96(10.7)$ & $62(10.4)$ & $34(1 \mathrm{I} .4)$ & \\
\hline Insurance status & & & & 0.962 \\
\hline Uninsured & $367(40.9)$ & $245(41.0)$ & $122(40.8)$ & \\
\hline Insured & $530(59.1)$ & $353(59.0)$ & $177(59.2)$ & \\
\hline Marital status & & & & 0.129 \\
\hline Unmarried & $40 \mathrm{I}(44.7)$ & $278(46.5)$ & $123(4||)$. & \\
\hline Married & $496(55.3)$ & $320(53.5)$ & $176(58.9)$ & \\
\hline
\end{tabular}

Note: ${ }^{* *}$ Indicates American Indian/AK Native, Asian/Pacific Islander, and unknown.

Abbreviation: AFP, alpha fetoprotein.

classification grade I, T stage, $\mathrm{N}$ stage, bone metastasis, AFP levels, marital status, treatment, radiation and chemotherapy were significantly associated with OS.

In the multivariate analysis, sex, $\mathrm{T}$ stage, bone metastasis, AFP levels, treatment, radiation and chemotherapy were identified as prognostic factors for OS.

\section{Construction and Validation of the Nomogram}

The nomogram was constructed using the seven significant prognostic factors listed above, which were generated from the multivariate analysis, to predict the 1-, 2- and 3-year OS of patients with HCC and pulmonary metastases (Figure 1). By adding the scores of the identified factors, we easily determined the probability of survival.

The $\mathrm{C}$-indexes of the nomogram for predicting OS were 0.661 (95\% CI: $0.633-0.688)$ and 0.657 (95\% CI: 0.626-0.698) for the primary and validation cohorts, respectively, which showed good predictive value of the nomogram. As shown in Figure 2, the calibration curves for 1-, 2- and 3-year OS suggested excellent agreement with the survival predicted by the nomogram and the actual observation in the primary cohort. In the validation cohort, the calibration curves also showed good consistency between the probability and observation in the nomogram.

\section{Discussion}

Patients with HCC and extrahepatic disease at the initial diagnosis have a poor prognosis. The most frequent site of extrahepatic metastasis in patients with HCC is the lung. Due to its lower incidence, previously published investigations $^{9-12}$ were primarily derived from case reports and single-institution experience, with relatively small sample sizes. Therefore, the largest population-based investigation conducted to date was performed to analyze the clinical characteristics, risk factors and prognostic factors and subsequently construct a novel and accurate nomogram for predicting the prognosis of patients with HCC presenting with pulmonary metastasis.

In the present study, we identified several factors, including an older age, nonwhite race, higher grade and $\mathrm{T}$ stage and metastatic lesions (bone, brain, and intrahepatic metastasis), correlated with greater odds of pulmonary metastasis at diagnosis. This nomogram indicated that if the patients had the above features, they should undergo additional measures for the early detection or prevention of pulmonary metastasis. Accordingly, we suggest that 
Table 3 Univariate and Multivariate Analysis of Overall Survival for the Primary Set

\begin{tabular}{|c|c|c|c|c|}
\hline \multirow[t]{2}{*}{ Characteristics } & \multicolumn{2}{|c|}{ Univariate Analysis } & \multicolumn{2}{|c|}{ Multivariate Analysis } \\
\hline & HR (95\% CI) & $\mathbf{P}$ & HR $(95 \% \mathrm{Cl})$ & $\mathbf{P}$ \\
\hline \multicolumn{5}{|l|}{ Age } \\
\hline$<50$ & I(Reference) & 1 & I (Reference) & 1 \\
\hline $50-60$ & I.II (0.86-I.44) & 0.410 & $1.26(0.96-1.64)$ & 0.091 \\
\hline $60-70$ & $1.13(0.88-1.47)$ & 0.333 & $1.19(0.91-1.55)$ & 0.204 \\
\hline $70-80$ & I.14(0.87-I.50) & 0.342 & $1.28(0.96-1.7 I)$ & 0.088 \\
\hline$>80$ & $1.07(0.77-1.47)$ & 0.677 & $1.14(0.82-1.59)$ & 0.425 \\
\hline \multicolumn{5}{|l|}{ Race } \\
\hline White & I(Reference) & 1 & I (Reference) & 1 \\
\hline Black & $1.03(0.86-1.23)$ & 0.747 & $0.98(0.82-1.18)$ & 0.871 \\
\hline Other** & $1.04(0.87-1.23)$ & 0.685 & $1.17(0.97-1.39)$ & 0.929 \\
\hline \multicolumn{5}{|l|}{ Sex } \\
\hline Female & I (Reference) & 1 & I (Reference) & 1 \\
\hline Male & $1.32(|| 7-,|.4|)$ & $0.038^{*}$ & $1.21(1.01-1.43)$ & $0.036^{*}$ \\
\hline \multicolumn{5}{|c|}{ Edmonson-Steiner classification } \\
\hline Unknown & I (Reference) & 1 & I (Reference) & 1 \\
\hline 1 & $0.74(0.56-0.99)$ & $0.040^{*}$ & $0.89(0.67-1.18)$ & 0.415 \\
\hline II & $0.82(0.67-1.00)$ & 0.055 & $0.97(0.79-1.18)$ & 0.747 \\
\hline III & $1.07(0.87-1.32)$ & 0.488 & $1.17(0.95-1.44)$ & 0.140 \\
\hline IV & $1.22(0.65-2.29)$ & 0.529 & $1.82(0.95-3.50)$ & 0.069 \\
\hline \multicolumn{5}{|l|}{ T stage } \\
\hline TI & I(Reference) & 1 & I (Reference) & 1 \\
\hline $\mathrm{T} 2$ & $1.39(1.10-1.75)$ & $0.006 *$ & $1.32(1.04-1.68)$ & $0.023^{*}$ \\
\hline T3 & $1.40(1.19-1.66)$ & $<0.001^{*}$ & $1.42(1.19-1.70)$ & $<0.001^{*}$ \\
\hline $\mathrm{T} 4$ & $1.40(1.13-1.75)$ & $0.002 *$ & $1.47(1.17-1.84)$ & $<0.001^{*}$ \\
\hline \multicolumn{5}{|l|}{$\mathrm{N}$ stage } \\
\hline No & I(Reference) & 1 & I (Reference) & 1 \\
\hline $\mathrm{NI}$ & $1.24(1.06-1.46)$ & $0.006 *$ & $1.07(0.90-1.26)$ & 0.437 \\
\hline \multicolumn{5}{|l|}{ Bone metastasis } \\
\hline None & I(Reference) & 1 & I (Reference) & I \\
\hline Yes & $1.20(1.00-1.44)$ & $0.045^{*}$ & $1.29(1.04-1.60)$ & $0.022 *$ \\
\hline \multicolumn{5}{|l|}{ Brain metastasis } \\
\hline None & I(Reference) & I & I (Reference) & I \\
\hline Yes & $1.20(0.75-1.91)$ & 0.455 & $1.15(0.70-1.87)$ & 0.580 \\
\hline
\end{tabular}


Table 3 (Continued).

\begin{tabular}{|c|c|c|c|c|}
\hline \multirow[t]{2}{*}{ Characteristics } & \multicolumn{2}{|c|}{ Univariate Analysis } & \multicolumn{2}{|c|}{ Multivariate Analysis } \\
\hline & HR (95\% Cl) & $\mathbf{P}$ & HR (95\% CI) & $\mathbf{P}$ \\
\hline \multicolumn{5}{|l|}{ Intrahepatic metastasis } \\
\hline None & I (Reference) & 1 & I (Reference) & 1 \\
\hline Yes & $1.08(0.85-1.38)$ & 0.543 & $0.96(0.75-1.23)$ & 0.752 \\
\hline \multicolumn{5}{|l|}{ AFP } \\
\hline Unknown & I(Reference) & 1 & I (Reference) & 1 \\
\hline Elevated & $0.99(0.82-1.22)$ & 0.969 & $1.00(0.81-1.25)$ & 0.965 \\
\hline Normal & $0.73(0.55-0.97)$ & $0.027^{*}$ & $0.75(0.56-0.83)$ & $0.032^{*}$ \\
\hline \multicolumn{5}{|l|}{ Insurance status } \\
\hline Uninsured & I (Reference) & 1 & I (Reference) & 1 \\
\hline Insured & $1.03(0.90-1.18)$ & 0.693 & $1.10(0.94-1.28)$ & 0.217 \\
\hline \multicolumn{5}{|l|}{ Marital status } \\
\hline Unmarried & I(Reference) & 1 & I (Reference) & 1 \\
\hline Married & $0.86(0.75-0.99)$ & $0.036^{*}$ & $0.94(0.8 I-I .10)$ & 0.449 \\
\hline \multicolumn{5}{|l|}{ Treatment } \\
\hline No surgery & I(Reference) & 1 & I (Reference) & 1 \\
\hline Local tumor destruction & $0.29(0.16-0.53)$ & $<0.00 I^{*}$ & $0.32(0.17-0.59)$ & $<0.001^{*}$ \\
\hline Hepatectomy & $0.36(0.20-0.66)$ & $<0.001^{*}$ & $0.34(0.18-0.63)$ & $<0.001^{*}$ \\
\hline \multicolumn{5}{|l|}{ Radiation } \\
\hline None & I(Reference) & 1 & I (Reference) & 1 \\
\hline Yes & $0.80(0.65-0.98)$ & $0.032 *$ & $0.67(0.53-0.86)$ & $0.001^{*}$ \\
\hline \multicolumn{5}{|l|}{ Chemotherapy } \\
\hline None & I(Reference) & 1 & I (Reference) & 1 \\
\hline Yes & $0.60(0.53-0.69)$ & $<0.001^{*}$ & $0.56(0.48-0.65)$ & $<0.001^{*}$ \\
\hline
\end{tabular}

Notes: *Indicates significance of $\mathrm{P}<0.05$. **Indicates American Indian/AK Native, Asian/Pacific Islander, and unknown.

Abbreviations: AFP, alpha fetoprotein; HR, hazard ratio; $\mathrm{Cl}$, confidence interval.

regular chest $\mathrm{CT}$ scans should be considered to diagnose pulmonary metastasis early. ${ }^{13}$

Several widely recognized staging systems are available for evaluating $\mathrm{HCC}$, such as the Barcelona Clinic Liver Cancer (BCLC) classification, TNM staging systems and American Joint Committee (AJCC) cancer staging system. ${ }^{14}$ Many variables were identified as prognostic factors and were included in cancer staging systems, including the tumor size, vascular invasion, performance status, distant metastases, and liver function indicators such as serum albumin and bilirubin levels. However, these staging systems and prognostic factors were only applied to patients with HCC without pulmonary metastasis. ${ }^{15}$ As shown in the present study, several prognostic variables, including sex, $\mathrm{T}$ stage, bone metastasis, AFP levels, treatment allocation, radiation and chemotherapy, were associated with OS and were then integrated into the nomogram for predicting the OS of patients with HCC presenting pulmonary metastasis. Among these factors, $\mathrm{T}$ stage, AFP levels, treatment, radiation and chemotherapy were most strongly associated with the OS of patients with HCC and pulmonary metastasis. According to 


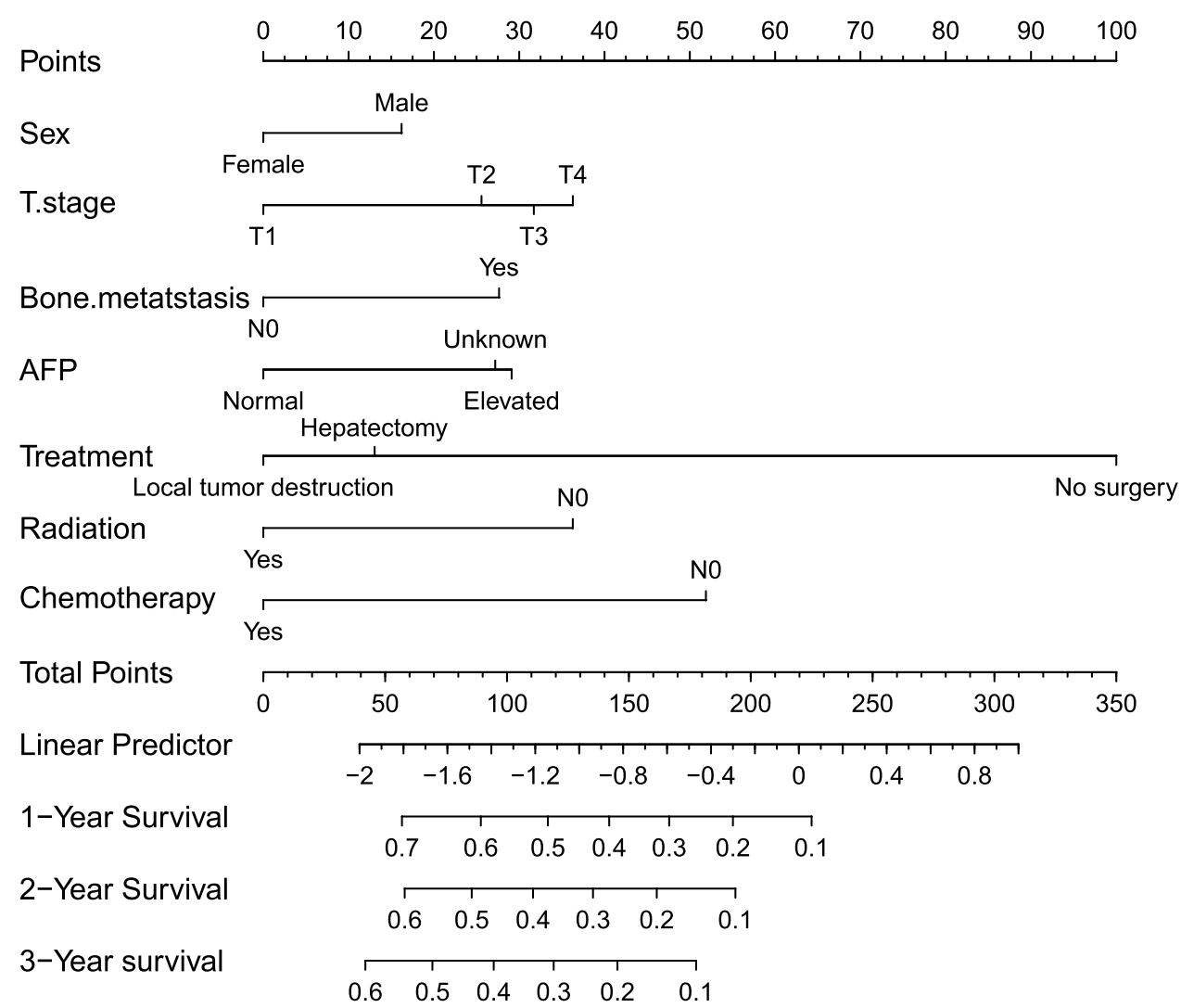

Figure I Nomogram for predicting the overall survival of patients with hepatocellular carcinoma (HCC) presenting with pulmonary metastasis.
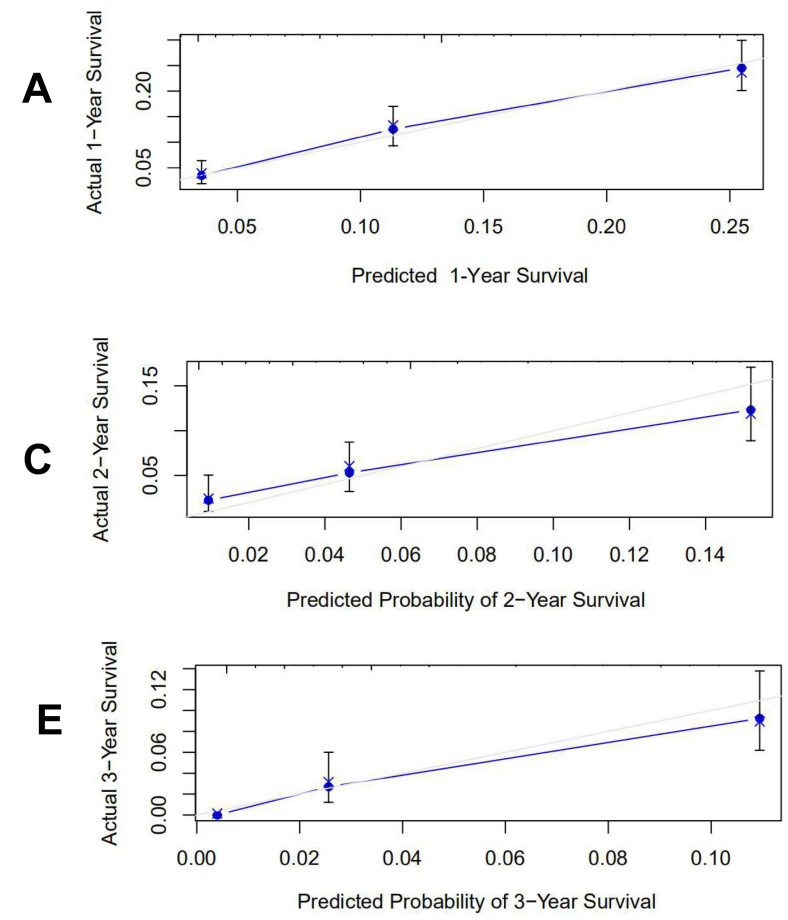
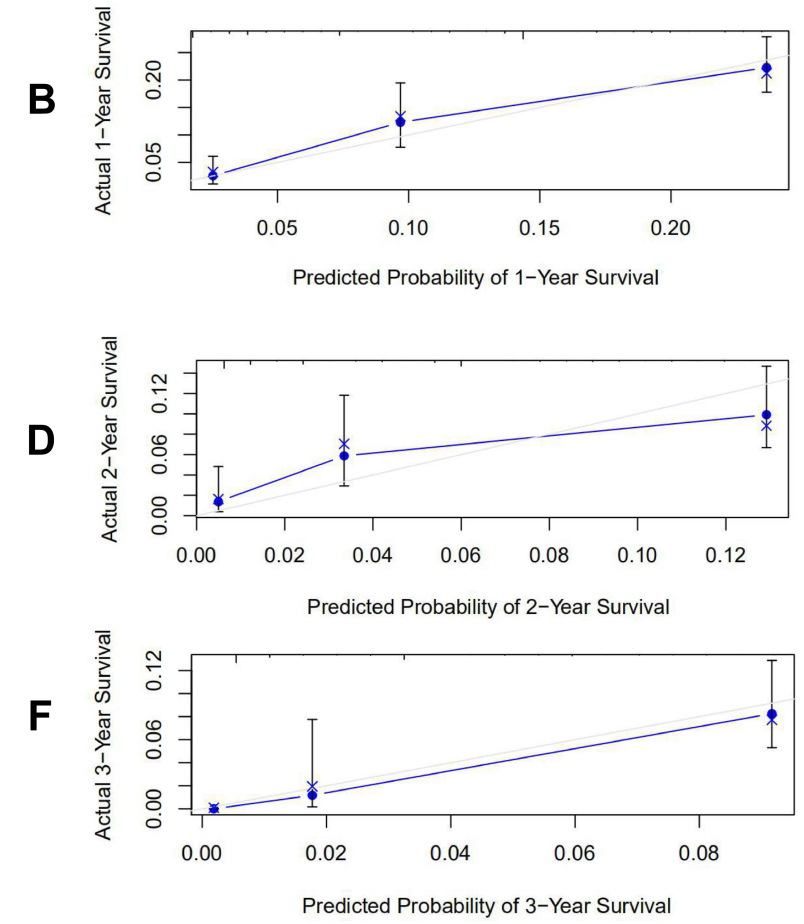

Figure 2 Calibration curves for the nomograms. The nomograms predicted the I- (A for the primary cohort, B for the validation cohort), 2-year (C for the primary cohort, $\mathbf{D}$ for the validation cohort) and 3-year (E for the primary cohort, $\mathbf{F}$ for the validation cohort) overall survival of patients with hepatocellular carcinoma (HCC) presenting with pulmonary metastasis. 
previous studies, ${ }^{16,17}$ the $\mathrm{T}$ stage is an important prognostic factor for survival or recurrence. A larger tumor size always occurs concomitantly with microscopic vascular invasion. Several staging systems have selected tumor size as an important prognostic factor. ${ }^{18}$ Dai et $\mathrm{al}^{19}$ reported a better prognosis and lower recurrence rate for patients with a tumor size $\leq 5 \mathrm{~cm}$ than patients with a tumor size $\geq 5 \mathrm{~cm}$. Another study ${ }^{20}$ based on a large population of 38,368 patients also revealed significant differences in the five-year CSS among subgroups with different tumor sizes $(\mathrm{p}<0.001)$. The results from our study were consistent with previous studies, indicating that a larger tumor size correlated with a worse prognosis. As an important diagnostic marker for liver cancer, AFP levels are important in determining the diagnosis and prognosis and are widely used in clinical practice. ${ }^{21}$ Abnormal AFP levels or increases in AFP levels after resection can help identify metastases or possible tumor recurrence. One study ${ }^{19}$ of 397 patients with HCC who underwent tumor resection found that patients with AFP levels $\geq 20 \mathrm{ng} / \mathrm{mL}$ had 2.2-fold higher mortality rate than patients with AFP levels $<20 \mathrm{ng} / \mathrm{mL}$. The results from our study also revealed that patients with HCC and pulmonary metastasis who presented normal AFP levels had a longer OS than patients with elevated AFP levels.

According to the clinical guidelines and consensus, ${ }^{2,3,22}$ patients with $\mathrm{HCC}$ who are diagnosed with pulmonary metastasis were classified as having advanced stage disease. The treatment modalities for this set of patients include systemic treatment, transarterial chemoembolization (TACE) and radiation. In our study, only a small percentage of patients underwent local tumor resection and hepatectomy, and those subgroups experienced longer OS than patients who did not receive these treatments. Regrettably, patients with HCC presenting pulmonary metastasis always have multiple lesions in the liver and vascular invasion, which is a contraindication for local treatment for HCC. Based on our results, the modality of radiation correlated with the survival outcome of patients with HCC presenting with pulmonary metastasis. Significant progress in radiotherapy technology has been attained, such as three-dimensional conformal radiotherapy characterized by lower radiotoxicity. ${ }^{23}$ Several published studies have reported the effectiveness of radiotherapy for patients with HCC presenting with portal vein tumor thrombosis. ${ }^{24-27}$ Bae et $\mathrm{al}^{28}$ reported the treatment of 47 patients with HCC complicated with PVTT using 3D-CRT and achieved a response rate of $40 \%$ and a 1 -year survival rate of $15 \%$. Patients with HCC presenting with pulmonary metastasis were classified as having advanced stage disease, which was always accompanied by portal vein thrombosis. Radiotherapy plays an important role in controlling portal vein thrombosis in patients with HCC, thus improving survival outcomes. In our study, this subpopulation who received chemotherapy achieved a better prognosis than patients who did not receive chemotherapy. Intrahepatic lesions and pulmonary metastasis are all refractory to systemic chemotherapy. However, several investigators ${ }^{29}$ have shown the benefit of transarterial chemotherapy infusion (TAI) for treating pulmonary metastasis from HCC. Based on the aforementioned results, one explanation for the benefit of chemotherapy in our study is that the modality of chemotherapy may be TAI, which was not described carefully in the SEER database.

Apart from the prognostic factors for OS listed above that were identified in our study, a series of studies reported other treatment modalities and characteristics related to survival outcomes. Tomimaru et $\mathrm{al}^{30}$ reported the data from 14 patients with pulmonary metastases from HCC, 8 of whom underwent pulmonary resection. The results showed a better prognosis and survival for patients who received pulmonary resection. Lee et $\mathrm{al}^{31}$ analyzed 32 patients who underwent surgical resection for pulmonary metastasis from HCC and reported a significantly longer median survival time after pulmonary resection than for patients without surgical treatment, with a disease-free time $\geq 12$ months. Based on these results, surgical resection for pulmonary metastasis from HCC might be a better option for some patients.

This large-scale study revealed the clinical characteristics, risk and prognostic factors for patients with HCC and pulmonary metastasis. Our study had several limitations that should be noted. First, as mentioned above, information on microvascular invasion (MVI), liver function and the Eastern Cooperative Oncology Group score could not be obtained from the SEER database. Second, details on chemotherapy were insufficient in the database. Finally, the database also lacks information on recurrence and laboratory parameters, which play crucial roles in determining the prognosis of patients with HCC presenting with pulmonary metastasis.

In conclusion, a list of risk factors associated with pulmonary metastasis occurrence was selected, and the nomogram accurately predicted the prognosis of patients with HCC and pulmonary metastasis at the initial diagnosis. 


\section{Ethical Approval}

All procedures performed in studies involving human participants were in accordance with the ethical standards of the institutional and national research committee and with the 1964 Helsinki declaration and its later amendments or comparable ethical standards. This study was approved by the Ethics Committee and Institutional Review Board of Zhongshan Hospital of Fudan University. We signed SEER data-use agreements to access the data retrieved from this data-set (ID:11,452-Nov2019). This study is based on the publicity available database without identifying patient information. All the patients were anonymized. So written informed consent was waived by the Ethics Committee and Institutional Review Board of Zhongshan Hospital.

\section{Acknowledgments}

We thank the SEER database for providing valuable dataset and our colleagues from the department for their support of this study. We thank the American Journal Experts (https://www.aje.com/) for editing this manuscript.

\section{Disclosure}

The authors have no conflicts of interest to declare.

\section{References}

1. Harding JJ, Abu-Zeinah G, Chou JF, et al. Frequency, morbidity, and mortality of bone metastases in advanced hepatocellular Carcinoma. $J$ Natl Compr Canc Netw. 2018;16(1):50-58. doi:10.6004/jnccn.20 17.7024

2. Galle PR, Forner A, Llovet JM, et al. EASL clinical practice guidelines: management of hepatocellular carcinoma. J Hepatol. 2018;69 (1): $182-236$.

3. Omata M, Cheng AL, Kokudo N, et al. Asia-Pacific clinical practice guidelines on the management of hepatocellular carcinoma: a 2017 update. Hepatol Int. 2017;11(4):317-370.

4. Natsuizaka M, Omura T, Akaike T, et al. Clinical features of hepatocellular carcinoma with extrahepatic metastases. J Gastroenterol Hepatol. 2005;20(11):1781-1787. doi:10.1111/j.1440-1746.2005.03919.x

5. Zhang S-M, Zeng Z-C, Tang Z-Y, et al. Prognostic analysis of pulmonary metastases from hepatocellular carcinoma. Hepatol Int. 2008;2 (2):237-243. doi:10.1007/s12072-008-9052-7

6. Karakiewicz PI, Briganti A, Chun FK, et al. Multi-institutional validation of a new renal cancer-specific survival nomogram. J Clin Oncol. 2007;25(11):1316-1322. doi:10.1200/JCO.2006.06.1218

7. Valentini V, van Stiphout RG, Lammering G, et al. Nomograms for predicting local recurrence, distant metastases, and overall survival for patients with locally advanced rectal cancer on the basis of European randomized clinical trials. J Clin Oncol. 2011;29(23):3163-3172. doi:10.1200/JCO.2010.33.1595

8. Song W, Zhu ZG, Wu Q, et al. A nomogram to predict overall survival for biliary tract cancer. Cancer Manag Res. 2018;10:1535-1541. doi:10.2147/CMAR.S163291

9. Hu Z, Huang P, Zhou Z, et al. Aggressive intrahepatic therapies for synchronous hepatocellular carcinoma with pulmonary metastasis. Clin Transl Oncol. 2018;20(6):729-739. doi:10.1007/s12094-017$1779-\mathrm{y}$
10. Ishii T, Hatano E, Yasuchika K, Taura K, Seo S, Uemoto S. High risk of lung metastasis after resection of hepatocellular carcinoma more than $7 \mathrm{~cm}$ in diameter. Surg Today. 2014;44(10):1900-1905.

11. Tanaka T, Hiramatsu K, Nosaka T, et al. Pituitary metastasis of hepatocellular carcinoma presenting with panhypopituitarism: a case report. BMC Cancer. 2015;15(1):863. doi:10.1186/s12885-015-1831-7

12. Takahashi Y, Ikeda N, Nakajima J, et al. Prognostic analysis of surgical resection for pulmonary metastasis from hepatocellular carcinoma. World J Surg. 2016;40(9):2178-2185. doi:10.1007/s00 268-016-3580-4

13. Pomerri F, Pucciarelli S, Maretto I, et al. Significance of pulmonary nodules in patients with colorectal cancer. Eur Radiol. 2012;22 (8):1680-1686. doi:10.1007/s00330-012-2431-4

14. Lee JI, Kim JK, Kim DY, et al. Prognosis of hepatocellular carcinoma patients with extrahepatic metastasis and the controllability of intrahepatic lesions. Clin Exp Metastasis. 2014;31(4):475-482. doi:10. 1007/s10585-014-9641-x

15. Yang A, Xiao W, Chen D, et al. The power of tumor sizes in predicting the survival of solitary hepatocellular carcinoma patients. Cancer Med. 2018;7(12):6040-6050. doi:10.1002/cam4.1873

16. Hwang S, Lee YJ, Kim KH, et al. The impact of tumor size on long-term survival outcomes after resection of solitary hepatocellular carcinoma: single-institution experience with 2558 patients. $J$ Gastrointest Surg. 2015;19(7):1281-1290. doi:10.1007/s11605015-2849-5

17. Goh BK, Teo JY, Chan CY, et al. Importance of tumor size as a prognostic factor after partial liver resection for solitary hepatocellular carcinoma: implications on the current AJCC staging system. J Surg Oncol. 2016;113(1):89-93. doi:10.1002/jso.24099

18. Subramaniam S, Kelley RK, Venook AP. A review of hepatocellular carcinoma (HCC) staging systems. Chin Clin Oncol. 2013;2(4):33. doi:10.3978/j.issn.2304-3865.2013.07.05

19. Dai CY, Lin CY, Tsai PC, et al. Impact of tumor size on the prognosis of hepatocellular carcinoma in patients who underwent liver resection. J Chin Med Assoc. 2018;81(2):155-163. doi:10.1016/j. jcma.2017.06.018

20. Zhang W, Jin K, Wang F, et al. Differences in the prognostic value of tumor size on hepatocellular cancer-specific survival stratified by gender in a SEER population-based study. United European Gastroenterol J. 2019;7(7):933-941. doi:10.1177/2050640619845602

21. Sauzay C, Petit A, Bourgeois AM, et al. Alpha-foetoprotein (AFP): a multi-purpose marker in hepatocellular carcinoma. Clin Chim Acta. 2016;463:39-44. doi:10.1016/j.cca.2016.10.006

22. Zhou J, Sun HC, Wang Z, et al. Guidelines for diagnosis and treatment of primary liver cancer in China (2017 edition). Liver Cancer. 2018;7(3):235-260. doi:10.1159/000488035

23. Liu PH, Huo TI, Miksad RA. Hepatocellular carcinoma with portal vein tumor involvement: best management strategies. Semin Liver Dis. 2018;38(3):242-251. doi:10.1055/s-0038-1666805

24. Lee SU, Park JW, Kim TH, et al. Effectiveness and safety of proton beam therapy for advanced hepatocellular carcinoma with portal vein tumor thrombosis. Strahlenther Onkol. 2014;190(9):806-814. doi:10. 1007/s00066-014-0604-6

25. Matsuo Y, Yoshida K, Nishimura $\mathrm{H}$, et al. Efficacy of stereotactic body radiotherapy for hepatocellular carcinoma with portal vein tumor thrombosis/inferior vena cava tumor thrombosis: evaluation by comparison with conventional three-dimensional conformal radiotherapy. J Radiat Res. 2016;57(5):512-523. doi:10.1093/jrr/ rrw028

26. Xi M, Zhang L, Zhao L, et al. Effectiveness of stereotactic body radiotherapy for hepatocellular carcinoma with portal vein and/or inferior vena cava tumor thrombosis. PLoS One. 2013;8(5):e63864. doi:10.1371/journal.pone.0063864

27. Yeh SA, Chen YS, Perng DS. The role of radiotherapy in the treatment of hepatocellular carcinoma with portal vein tumor thrombus. J Radiat Res. 2015;56(2):325-331. doi:10.1093/jrr/rru104 
28. Bae BK, Kim JC. The response of thrombosis in the portal vein or hepatic vein in hepatocellular carcinoma to radiation therapy. Radiat Oncol J. 2016;34(3):168-176. doi:10.3857/roj.2016.01669

29. Nakanishi M, Umeda Y, Demura Y, et al. Effective use of multi-arterial infusion chemotherapy for advanced non-small cell lung cancer patients: four clinical specified cases. Lung Cancer. 2007;55(2):241-247. doi:10.1016/j.lungcan.2006.10.008
30. Tomimaru Y, Sasaki Y, Yamada T, et al. The significance of surgical resection for pulmonary metastasis from hepatocellular carcinoma. Am J Surg. 2006;192(1):46-51. doi:10.1016/j.amjsurg.2005.12.006

31. Lee CY, Bae MK, Park IK, et al. Surgical resection for pulmonary metastasis from hepatocellular carcinoma: analysis of prognosis in relation to primary control. J Surg Oncol. 2010;101(3):239-243.

\section{Publish your work in this journal}

Cancer Management and Research is an international, peer-reviewed open access journal focusing on cancer research and the optimal use of preventative and integrated treatment interventions to achieve improved outcomes, enhanced survival and quality of life for the cancer patient.
The manuscript management system is completely online and includes a very quick and fair peer-review system, which is all easy to use. Visit http://www.dovepress.com/testimonials.php to read real quotes from published authors. 